\title{
The Golden Ratio
}

\section{Csizmadia Jozsef}

Inovator plus Ltd. Kanjiza, Kanjiza, Serbia

Email: savap123456@hotmail.com

How to cite this paper: Jozsef, C. (2016) The Golden Ratio. Journal of Modern Physics, 7, 1944-1948.

http://dx.doi.org/10.4236/jmp.2016.714171

Received: August 22, 2016

Accepted: October 23, 2016

Published: October 27, 2016

Copyright $\odot 2016$ by author and Scientific Research Publishing Inc. This work is licensed under the Creative Commons Attribution International License (CC BY 4.0).

http://creativecommons.org/licenses/by/4.0/

\section{Abstract}

The Lorentz transformation (if $x=c t$ ) is the same the golden ratio:

$\frac{t^{\prime}}{t}=\frac{1-v / c}{\sqrt{1-v^{2} / c^{2}}}=\frac{\sqrt{5}-1}{2}=0.618$.

\section{Keywords}

Lorentz Transformation, Relativity, Golden Ratio

\section{Introduction}

So, the aim of this work is to derive the golden ratio connected to Lorentz transformation. Usually the golden ratio is derived from the a rectangle [1] but book [2] derives the golden ratio from a right-angled triangle. This makes possible to connect Lorentz transformation with the golden ratio. The Lorentz factor formula can be the easiest explained from the right-angled triangle. The formula $\sqrt{c^{2}-v^{2}}$ is in fact the formula of one of the right-angled triangle side:

1) $\sqrt{c^{2}-v^{2}}=c \sqrt{1-\left(v^{2} / c^{2}\right)}$

It can be seen from this formula also that " $c$ " is the hypotenuse of the right-angled triangle. At the same time " $c>v$ " is one criterion of Lorentz factor formula as well. That means, that the hypotenuse of the right-angled triangle is " $c$ ", the other sides is " $V$ " and $\sqrt{c^{2}-v^{2}}$. This allows that from so defined right-angled triangle to explain the formula of Lorentz transformation too and the golden ratio formula as well. For the derivation of the equations high school mathematics is used. That's the reason why the equations are more transparent and easier to understand because they are simply.

\section{We Introduce First the $\left(t^{\prime} / t\right)$ Formula}

The derivation of Lorentz transformation can be found at the end of the book marked 
by [3] in the Appendix I. The derivation of Lorentz transformation equations starts from the fact that we measure two light-rays move face each other, in a standing and in a moving coordinate system. So the travelled distance of the light-ray in the standing coordinate system is $x=c t$. Naturally in the movable coordinate system the travelled distance of the light-ray is $x^{\prime}=c t^{\prime}$. Here it can be seen that Lorentz's starting point were a few assumptions, (see [3] Appendix I) and from these simple assumptions got the formula named after him. After that Einstein substituted in the Lorentz transformation equation $t^{\prime}$, the equation of $x=c t$. This derivation can be found in the book marked number [3] on the page 32. Now I show this derivation.

2) So, $x=c t$ and $x / c=t$ :

$$
t^{\prime}=\frac{t-\left(v / c^{2}\right) x}{\sqrt{1-\left(v^{2} / c^{2}\right)}}=\frac{t-(v / c)(x / c)}{\sqrt{1-\left(v^{2} / c^{2}\right)}}=\frac{t-(v / c) t}{\sqrt{1-\left(v^{2} / c^{2}\right)}}=t \frac{1-(v / c)}{\sqrt{1-\left(v^{2} / c^{2}\right)}}
$$

3) Equation $\left(t^{\prime} / t\right)$ :

$$
\frac{t^{\prime}}{t}=\frac{1-(v / c)}{\sqrt{1-\left(v^{2} / c^{2}\right)}}
$$

We are going to prove that the equation 3) is the golden ratio.

\subsection{Now We Derive the Other Form of the Equation (3)}

Before we start with the derivation of the golden ratio, we transform the Equation (3).

4) In further derivation we shall use the following equations from the Appendix I of the book [3]:

$$
a=\frac{1}{\sqrt{1-\left(v^{2} / c^{2}\right)}} ; \quad b=\frac{(v / c)}{\sqrt{1-\left(v^{2} / c^{2}\right)}}
$$

5) In further derivation we shall use the following equations from the [4]:

$$
\xi=\operatorname{artanh}(v / c)
$$

$(-1.0<(v / c)<1.0$ See the Figure 1).

6) From the [4] we take also the following equations:

$$
\cosh \xi=\frac{1}{\sqrt{1-\left(v^{2} / c^{2}\right)}} ; \quad \sinh \xi=\frac{(v / c)}{\sqrt{1-\left(v^{2} / c^{2}\right)}}
$$

7) We shall transform the Equation (3) and take the Equation (4) and Equation(5) and Equation (6) into account:

$$
\frac{t^{\prime}}{t}=\frac{1-(v / c)}{\sqrt{1-\left(v^{2} / c^{2}\right)}}=\frac{1}{\sqrt{1-\left(v^{2} / c^{2}\right)}}-\frac{(v / c)}{\sqrt{1-\left(v^{2} / c^{2}\right)}}=a-b=\cosh \xi-\sinh \xi=\mathrm{e}^{-\xi}
$$

8) So:

$$
\frac{t^{\prime}}{t}=\frac{1-(v / c)}{\sqrt{1-\left(v^{2} / c^{2}\right)}}=\mathrm{e}^{-\xi}=\mathrm{e}^{-\operatorname{artanh}(v / c)}=\frac{1}{\mathrm{e}^{\operatorname{artanh}(v / c)}}
$$

The Equation (8) can be found in [5]. 


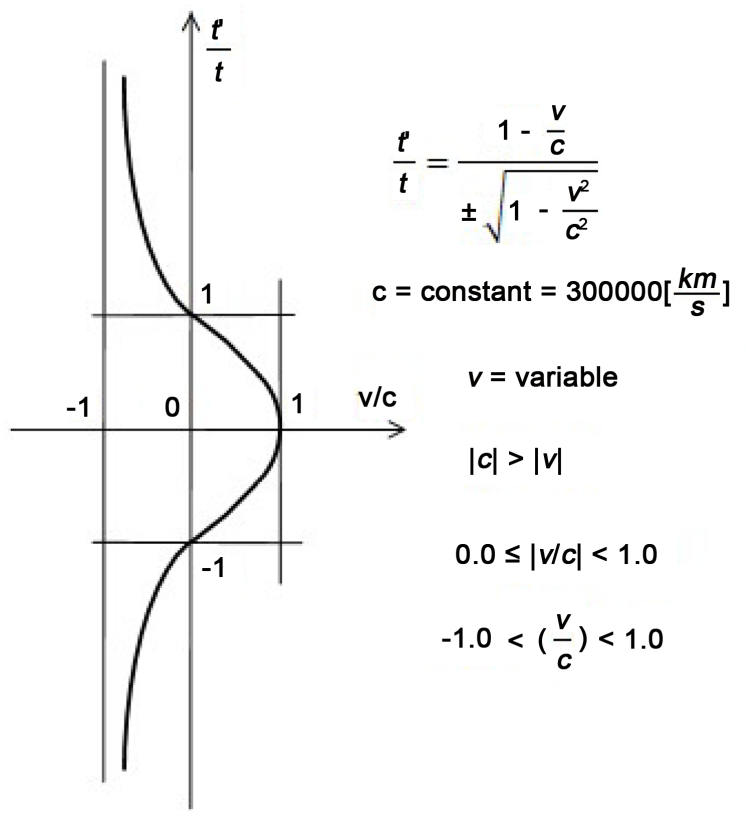

Figure 1. The Equation (8).

\subsection{Derivation of the Golden Ratio}

We mentioned in the introduction, the formula of golden ratio, we are going to derive it from a right-angled triangle [2]. (Note: Figure 2 can be found in [2]).

9) See Figure 2: $\quad F=2 v=\sqrt{c^{2}-v^{2}}$

$$
c^{2}-v^{2}=(2 v)^{2} \rightarrow c^{2}-v^{2}=4 v^{2} \rightarrow c^{2}=5 v^{2} \rightarrow v=c \frac{1}{\sqrt{5}}
$$

10) The golden ratio:

$$
\frac{O E}{O A}=\frac{c-v}{F}=\frac{c-v}{2 v}=\frac{c-c \frac{1}{\sqrt{5}}}{2 c\left[\frac{1}{\sqrt{5}}\right]}=\frac{\sqrt{5}-1}{2}
$$

11) See Equation (9):

$$
v=c \frac{1}{\sqrt{5}} \rightarrow \frac{v}{c}=\frac{1}{\sqrt{5}}
$$

12) Now we transform the Equation (10) so that it should be equal with Equation (8). We will take into account that:

$$
\begin{gathered}
F=2 v=\sqrt{c^{2}-v^{2}} \\
\frac{O E}{O A}=\frac{c-v}{F}=\frac{c-v}{2 v}=\frac{c(1-v / c)}{c \sqrt{1-v^{2} / c^{2}}}=\frac{1-v / c}{\sqrt{1-v^{2} / c^{2}}}=\frac{\sqrt{5}-1}{2}=0.618
\end{gathered}
$$

13) Of course, the Equation (12) is identical with Equation (8):

$$
\frac{t^{\prime}}{t}=\frac{1-(v / c)}{\sqrt{1-\left(v^{2} / c^{2}\right)}}=\mathrm{e}^{-\xi}=\mathrm{e}^{-\operatorname{artanh}(v / c)}=\frac{1}{\mathrm{e}^{\operatorname{artanh}(v / c)}}=\frac{\sqrt{5}-1}{2}
$$




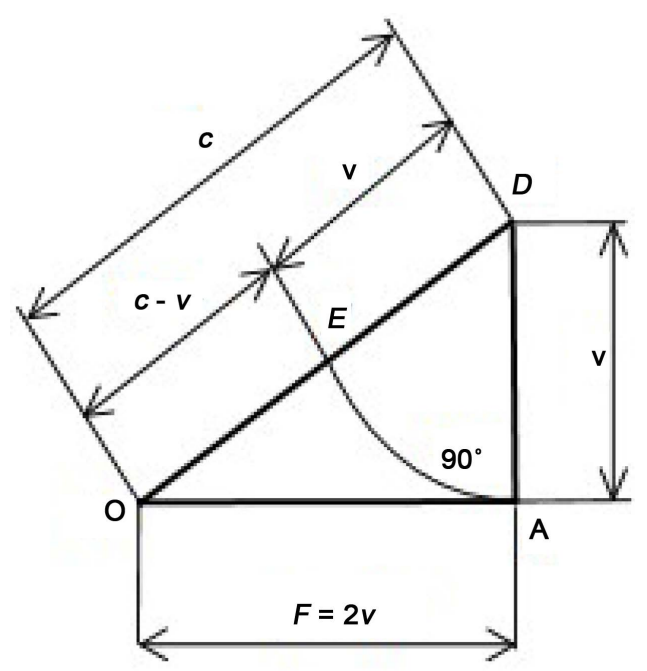

Figure 2. In the book [2] the golden ratio $=O E / O A$, and $F=2 v$.

\section{Conclusion}

It can be seen in the Equation (13) that $t^{\prime} / t$ equation can be expressed in more ways. But every equation is the equation of golden ratio. Naturally the golden ratio appears only then if $(v / c)=1 / \sqrt{5}$.

14) The Equation (13):

$$
\frac{\sqrt{5}-1}{2}=\frac{1}{\frac{\sqrt{5}+1}{2}}=\mathrm{e}^{-\xi}=\mathrm{e}^{-\operatorname{artanh}(v / c)}=0.618
$$

15) So:

$$
\frac{\sqrt{5}+1}{2}=\mathrm{e}^{\xi}=\mathrm{e}^{\operatorname{artanh}(v / c)}=1.61803
$$

\section{Discussion}

Naturally the golden ratio often appears in physics. Hardy suggest to use the golden ratio (See E. Naschi work, references [6]. Lorentz transformation equation is the same as suggested by Hardy. It would be good to prove in other way the connection of two equations. That's the reason why the two equations are not unambiguous:

16) The Hardy equation [6], and the Equation (13):

$$
\Phi=\text { Golden ratio }=\mathrm{e}^{-\operatorname{artanh}\left(\frac{1}{\sqrt{5}}\right)}
$$

17) But still it is interesting the Equation (11) trivial solution:

$$
\text { equation (9) }: v=c \frac{1}{\sqrt{5}} \rightarrow c=300000[\mathrm{~km} / \mathrm{s}] \text { and } v=\left(\frac{300000}{\sqrt{5}}\right)[\mathrm{km} / \mathrm{s}]
$$

\section{References}

[1] Golden Ratio. https://en.wikipedia.org/wiki/Golden_ratio 
[2] Bronstejn I.N. and Szemengyajev, K.A. (1982) Matematikai zsebkonyv. Translate: Mathematical Pocketbook. Muszaki konyvkiado, Budapest.

[3] Einstein, A. (1921) Relativity: The Special and the General Theory. METHUEN and CO. LTD., London. http://www.gutenberg.lib.md.us/3/6/1/1/36114/36114-pdf.pdf

[4] https://en.wikipedia.org/wiki/Lorentz_transformation

[5] Trasformazione di Lorentz. https://it.wikipedia.org/wiki/Trasformazione_di_Lorentz

[6] El Naschie, M. (2016) Journal of Modern Physics, 7, 1420-1428. http://dx.doi.org/10.4236/jmp.2016.712129

Submit or recommend next manuscript to SCIRP and we will provide best service for you:

Accepting pre-submission inquiries through Email, Facebook, LinkedIn, Twitter, etc. A wide selection of journals (inclusive of 9 subjects, more than 200 journals)

Providing 24-hour high-quality service

User-friendly online submission system

Fair and swift peer-review system

Efficient typesetting and proofreading procedure

Display of the result of downloads and visits, as well as the number of cited articles Maximum dissemination of your research work

Submit your manuscript at: http://papersubmission.scirp.org/

Or contact jmp@scirp.org 